\title{
Acute-on-chronic liver failure: consensus recommendations of the Asian Pacific Association for the Study of the Liver (APASL) 2014
}

\author{
Shiv Kumar Sarin - Chandan Kumar Kedarisetty - Zaigham Abbas • Deepak Amarapurkar • \\ Chhagan Bihari - Albert C. Chan · Yogesh Kumar Chawla · A. Kadir Dokmeci · Hitendra Garg • \\ Hasmik Ghazinyan · Saeed Hamid • Dong Joon Kim · Piyawat Komolmit · Suman Lata • \\ Guan Huei Lee $\cdot$ Laurentius A. Lesmana $\cdot$ Mamun Mahtab $\cdot$ Rakhi Maiwall $\cdot$ Richard Moreau \\ Qin Ning · Viniyendra Pamecha - Diana Alcantara Payawal - Archana Rastogi - Salimur Rahman · \\ Mohamed Rela • Anoop Saraya · Didier Samuel • Vivek Saraswat · Samir Shah · Gamal Shiha · \\ Brajesh Chander Sharma • Manoj Kumar Sharma · Kapil Sharma • Amna Subhan Butt • \\ Soek Siam Tan $\cdot$ Chitranshu Vashishtha $\cdot$ Zeeshan Ahmed Wani $\cdot$ Man-Fung Yuen • \\ Osamu Yokosuka $\cdot$ the APASL ACLF Working Party
}

Received: 4 April 2014/ Accepted: 25 August 2014/Published online: 26 September 2014 (C) Asian Pacific Association for the Study of the Liver 2014

\begin{abstract}
The first consensus report of the working party of the Asian Pacific Association for the Study of the Liver (APASL) set up in 2004 on acute-on-chronic liver failure (ACLF) was published in 2009. Due to the rapid advancements in the knowledge and available information, a consortium of members from countries across Asia Pacific, "APASL ACLF Research Consortium (AARC)," was formed in 2012. A large cohort of retrospective and prospective data of ACLF patients was collated and followed up in this data base. The current ACLF definition was reassessed based on the new AARC data base. These
\end{abstract}

S. K. Sarin $(\bowtie) \cdot$ C. K. Kedarisetty · H. Garg · R. Maiwall . M. K. Sharma - K. Sharma - C. Vashishtha - Z. A. Wani Department of Hepatology, Institute of Liver and Biliary Sciences, New Delhi 110070, India

e-mail: shivsarin@gmail.com

Z. Abbas

Department of Hepatogastroenterology, Sindh Institute of Urology and Transplantation, Karachi, Pakistan

D. Amarapurkar

Department of Gastroenterology and Hepatology, Bombay

Hospital and Medical Research, Mumbai, India

C. Bihari · A. Rastogi

Department of Pathology, Institute of Liver and Biliary Sciences, New Delhi 110070, India

\section{A. C. Chan}

Division of Hepatobiliary and Pancreatic Surgery, and Liver Transplantation, Department of Surgery, The University of Hong Kong, Hong Kong, China initiatives were concluded on a 2-day meeting in February 2014 at New Delhi and led to the development of the final AARC consensus. Only those statements which were based on the evidence and were unanimously recommended were accepted. These statements were circulated again to all the experts and subsequently presented at the annual conference of the APASL at Brisbane, on March 14, 2014. The suggestions from the delegates were analyzed by the expert panel, and the modifications in the consensus were made. The final consensus and guidelines document was prepared. After detailed deliberations and data analysis, the

\section{Y. K. Chawla}

Department of Hepatology, Post Graduate Institute of Medical Education and Research, Chandigarh, India

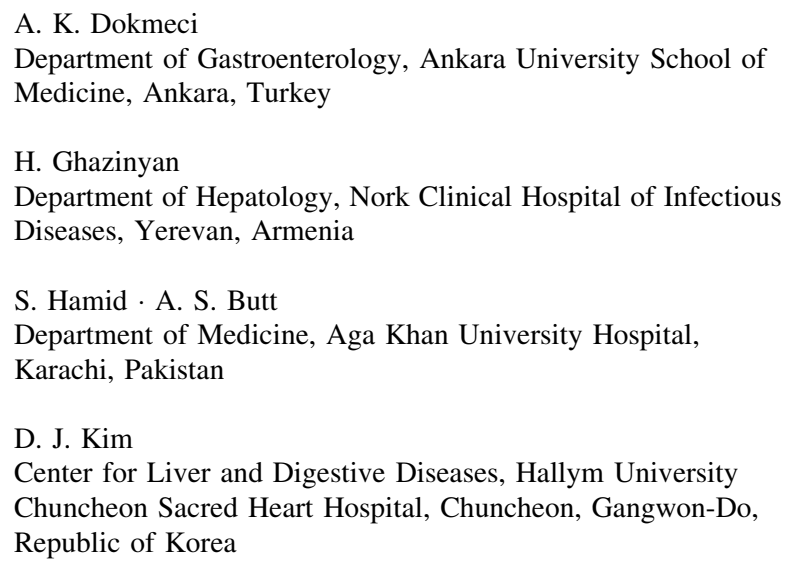


original proposed definition was found to withstand the test of time and identify a homogenous group of patients presenting with liver failure. Based on the AARC data, liver failure grading, and its impact on the "Golden therapeutic Window," extra-hepatic organ failure and development of sepsis were analyzed. New management options including the algorithms for the management of coagulation disorders, renal replacement therapy, sepsis, variceal bleed, antivirals, and criteria for liver transplantation for ACLF patients were proposed. The final consensus statements along with the relevant background information are presented here.

Keywords Liver failure - Chronic liver disease . Cirrhosis - Ascites - Acute liver failure and Scute liver failure

\section{Introduction}

Liver failure is a common medical ailment, and its incidence is increasing with the use of alcohol and growing epidemic of obesity and diabetes. It can present as acute liver failure (ALF) (in the absence of any preexisting liver disease), acute-on-chronic liver failure (ACLF) (an acute deterioration of known or unknown chronic liver disease), or an acute decompensation of an end-stage liver disease. Each of these is a well-defined disease entity with a homogenous population of patients with expected outcomes. Due to an overlap and lack of clarity of definitions and outcomes, entities like late-onset liver failure and subacute hepatic failure have become less relevant and are not often used.

\section{P. Komolmit}

Division of Gastroenterology and Hepatology, Department of Medicine, Chulalongkorn University, Bangkok, Thailand

S. Lata

Department of Nephrology, Institute of Liver and Biliary

Sciences, New Delhi 110070, India

G. H. Lee

Department of Gastroenterology and Hepatology, National University Health System, Singapore, Singapore

\section{A. Lesmana}

Division of Hepatology, University of Indonesia, Jakarta, Indonesia

\section{Mahtab · S. Rahman}

Department of Hepatology, Bangabandhu Sheikh Mujib Medical University, Dhaka, Bangladesh

\section{R. Moreau}

Inserm, U1149, Centre de recherche sur l'Inflammation (CRI), Paris, France
The growing interest in ACLF after the first consensus definition of ACLF from APASL [1] is evident by the fact that more than 200 publications as full paper have been published and the trend is surely increasing. A seminal paper from the EASL-CLIF consortium on the definition and outcome of ACLF has since appeared [2] based on the work of experts from several European and Western countries. The group of investigators working on liver failure in the AsiaPacific region working for the past decade carefully analyzed the patient characteristics, natural history, and outcome over the years. The group met on yearly basis and collated data on Web site (www.aclf.in) since 2009. The data were analyzed at meeting in China and Dhaka in 2012, with the setting up of the APASL ACLF Research Consortium (AARC). The retrospective and prospective data of patients from different centers were analyzed, and the completed patient records were utilized for defining predictors of mortality and grades of liver failure and incidence of other organ failures.

Experts from all over the globe, especially from the Asia-Pacific region, and members of the first consensus group were requested to identify pertinent and contentious issues in ACLF. Six major contentious issues and unmet needs in the management of ACLF were approached for the update: (1) what constitutes an acute insult; (2) whether chronic liver disease should be included or only cirrhosis of the liver in defining underlying liver disease; (3) the role of SIRS and sepsis as a cause or consequence of liver failure; (4) the incidence and impact of non-hepatic organ failures; (5) the relevance and grades of liver failure, the urgency, and outcome of liver transplant; and (6) an AARC prediction model of outcome of ACLF. The process for the development of the recommendations and guidelines included review of all available published literature on

\section{R. Moreau}

UMR_S 1149, Labex INFLAMEX, Université Paris Diderot Paris 7, Paris, France

\section{R. Moreau}

Département Hospitalo-Universitaire (DHU) UNITY, Service d'Hépatologie, Hôpital Beaujon, APHP, Clichy, France

Q. Ning

Department of Infectious Disease, Tongji Hospital of Tongji

Medical College, Huazhong University of Science and

Technology, Wuhan, China

V. Pamecha

Department of Hepatobiliary Surgery, Institute of Liver and Biliary Sciences, New Delhi 110070, India

D. A. Payawal

Department of Hepatology, Cardinal Santos Medical Center, Manila, Philippines 
ACLF by individual and group of experts; preparation of a review manuscript and consensus statements based on Oxford system of evidence-based approach [3] for developing the consensus statements, circulation of all consensus statements to all experts, an effort to define the acute hepatic insults; the underlying chronic liver disease, a survey of the current approaches for the diagnosis and management of ACLF; discussion on contentious issues; and deliberations to prepare the consensus statement by the experts of the working party. A 2-day meeting was held on February 22-23, 2014, at New Delhi, India, to discuss and finalize the recommendations and guidelines. These statements were circulated to all the experts, posted on the AARC Web site (www.aclf.in), and subsequently finalized. These consensus statements and guidelines for the management of such patients are included in this review. A brief background is included providing the available data and published information on each issue. Statements from the first consensus have been reproduced at places to give a background and continuity.

\section{The concept of ACLF and need for a definition}

Acute liver failure is a well-defined medical emergency which is defined as a severe liver injury, leading to coagulation abnormality usually with an INR $\geq 1.5$, and any degree of mental alteration (encephalopathy) in a patient without pre-existing liver disease and with an illness of up to 4 weeks duration [4]. A proportion of patients who present with features mimicking ALF, however, have an underlying chronic liver disease or cirrhosis of the liver. These patients grouped together as acute-on-chronic liver failure (ACLF) also have a poor outcome. These patients are distinctly different from a group of cirrhotic patients who are already decompensated and have a sudden

\section{Rela}

Institute of Liver Diseases and Transplantation, Global Health City, Chennai, India

\section{A. Saraya \\ Department of Gastroenterology, All India Institute of Medical Sciences, New Delhi, India \\ D. Samuel \\ INSERM, Centre Hépatobiliarie, Hôpital Paul Brousse, Villejuif, France}

\section{Saraswat}

Department of Gastroenterology, Sanjay Gandhi Post Graduate Institute of Medical Sciences, Lucknow, India

\section{S. Shah}

Department of Gastroenterology and Hepatology, Global Hospitals, Mumbai, India worsening of their condition due to an acute event as liver failure is central.

The ACLF is a clinical syndrome manifesting as acute and severe hepatic derangements resulting from varied insults. This term was first used in 1995 to describe a condition in which two insults to liver are operating simultaneously, one of them being ongoing and chronic, and the other acute [5]. Over the years, nearly thirteen different definitions have been proposed, creating confusion in the field [6]. Any patient who has an underlying chronic liver disease with superimposed acute insult is being labeled as having ACLF, irrespective of evidence of liver failure per se or evidence of preexisting cirrhotic decompensation. Several investigators were concerned that this would lead to overlap with decompensated liver disease. The main emphasis of the third consensus meeting of the APASL working party was to identify from this large group of patients, a subset of patients who have a relatively homogenous presentation and potentially similar outcome and restrict the use of the term "acute-on-chronic liver failure' to this subset. The 2009 APASL definition had provided a basis to select patients presenting with a distinct syndrome. To cover the entire spectrum of these patients, from mild to most severe, patients with chronic liver disease with or without cirrhosis of the liver were included and carefully analyzed. It is understandable, though not well defined, that the nature and degree acute insult and the status of the underlying chronic liver disease would determine the outcome of the patient (Fig. 1).

To give clarity to the primary event, a hepatic insult, jaundice and coagulopathy, which defined liver failure was considered essential. In acute liver failure, though hepatic encephalopathy is part of the definition, it follows liver failure. Encephalopathy in the absence of overt jaundice or liver failure is separately categorized as due to by-pass [7]. Should one wait for defining the outcome of "liver failure"

\section{G. Shiha}

Department of Internal Medicine, Egyptian Liver Research Institute and Hospital, Cairo, Egypt

B. C. Sharma

Department of Gastroenterology, GB Pant Hospital, New Delhi, India

S. S. Tan

Department of Gastroenterology and Hepatology, Selayang Hospital, Kepong, Malaysia

M.-F. Yuen

Department of Medicine, The University of Hong Kong, Hong Kong, China

O. Yokosuka

Department of Gastroenterology and Nephrology, Graduate School of Medicine, Chiba University, Chiba, Japan 
Fig. 1 In a setting of a normal hepatic reserve, an acute insult can lead to acute liver failure. The hepatic reserve can be restored to normal by newer treatment options or transplant. In setting of a reduced hepatic reserve as seen in chronic liver disease (chronic hepatitis or compensated cirrhosis of liver), an acute insult leads to acuteon-chronic liver failure with a high short-term mortality. However, there is a potential of reversibility by treating in the therapeutic golden window. This is a short window of few days, where in the liver failure is just below the organ threshold of optimal function and extrahepatic organ failure has not setin

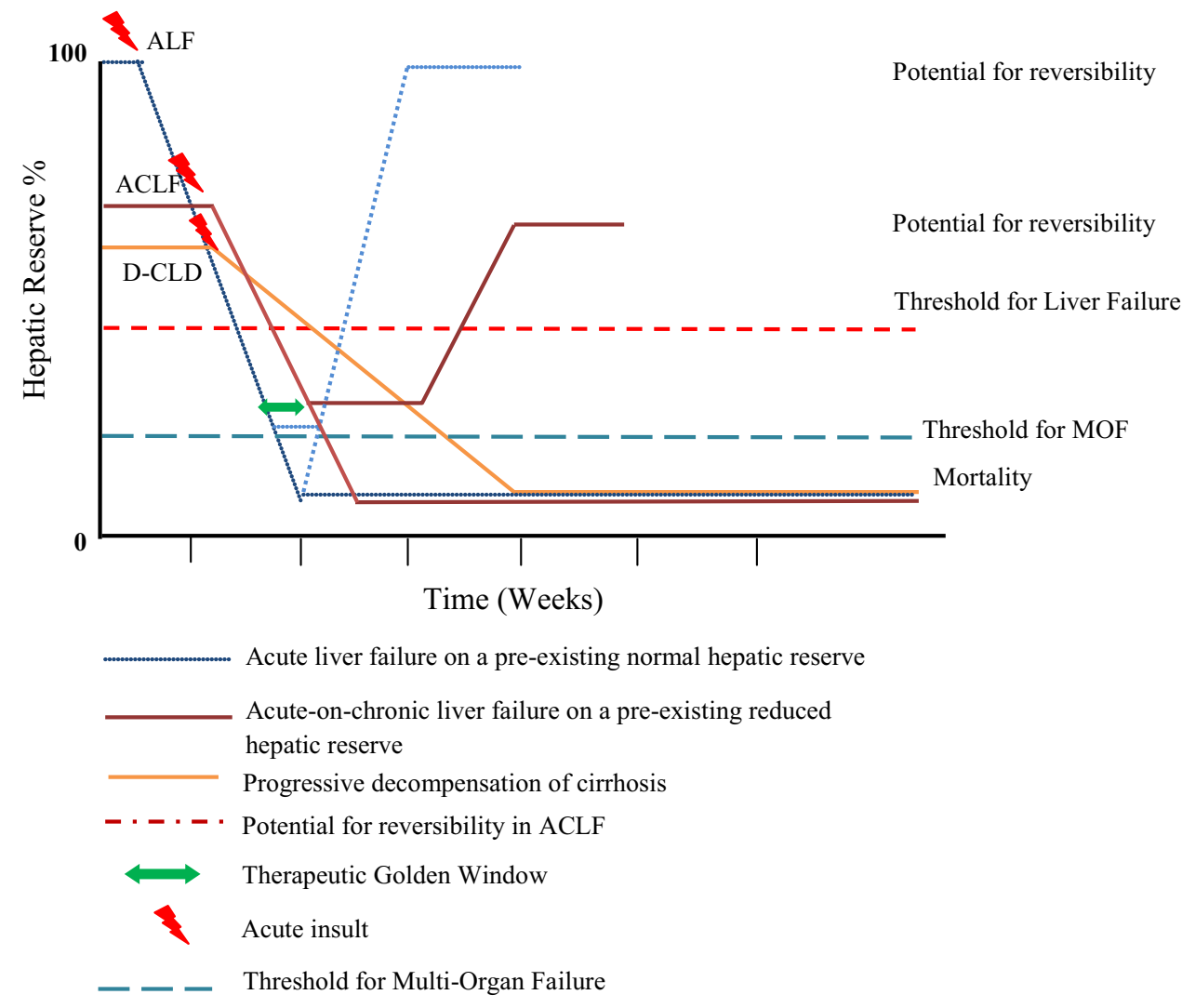

till the time extra-hepatic organ failures set in or not remain contentious. For definition, the event must be universally present in all patients. From the point of view of intensivists, it is well known that with increasing number of organ dysfunction or failure, the mortality would cumulatively increase. Undoubtedly, these events are predictive of the outcome, the basis of SOFA score. It is therefore not surprising; the same has been reported in the CANONIC study [2]. However, should organ failure be included in defining the clinical syndrome of liver failure needs a thorough analysis. As a corollary, despite decades of extensive experience, renal or circulatory dysfunction has not been included in the definition of ALF. The issue whether sepsis per se could lead to liver failure or is a result of liver failure had been debated for many years and was again revisited. However, sepsis is an integral part of development of multi-organ failure in any patient, be it of renal, pancreatic, or cardiac origin. The differences between the current definitions of CLIF consortium and APASL have been recently published [8].

While the first APASL consensus was based on the data of only about 200 patients, the data of 1700 patients are now available from 14 countries. Records of 1,363 ACLF patients were analyzed. This formed the basis of re-evaluating the validity of the APASL 2009 consensus. It was decided that, like in other studies, the analysis of the original data should be sent for separate publications and only the conclusions and recommendations based on these data can be used for the purpose of the consensus. To improve our understanding of the West, Prof Richard Moreau, the first author of the CANONIC study, kindly consented to join the consensus meeting.

The 6 major issues as mentioned above, and 28 subissues, were defined, and systematic reviews were made available to all participants. These were addressed at length in the meeting.

\section{What constitutes an acute insult}

This issue was divided into two parts: first, what is the time frame for the term "acute," and second, what are the criteria to define the nature of an "insult." A review of the different published definitions of acute liver failure and ACLF was done, and the current APASL definition of ACLF was reassessed. It was clear that the event must be new and acute, and its impact on the patient's condition should be observable as liver failure within a given time frame. The EASL-AASLD consortium had initially kept the assessment of outcomes at 3 months [9], but subsequently revised it to 28 days in the recent CANONIC study [2]. The AARC data were carefully analyzed, and the 
Fig. 2 Acute and chronic insults in ACLF and outcome

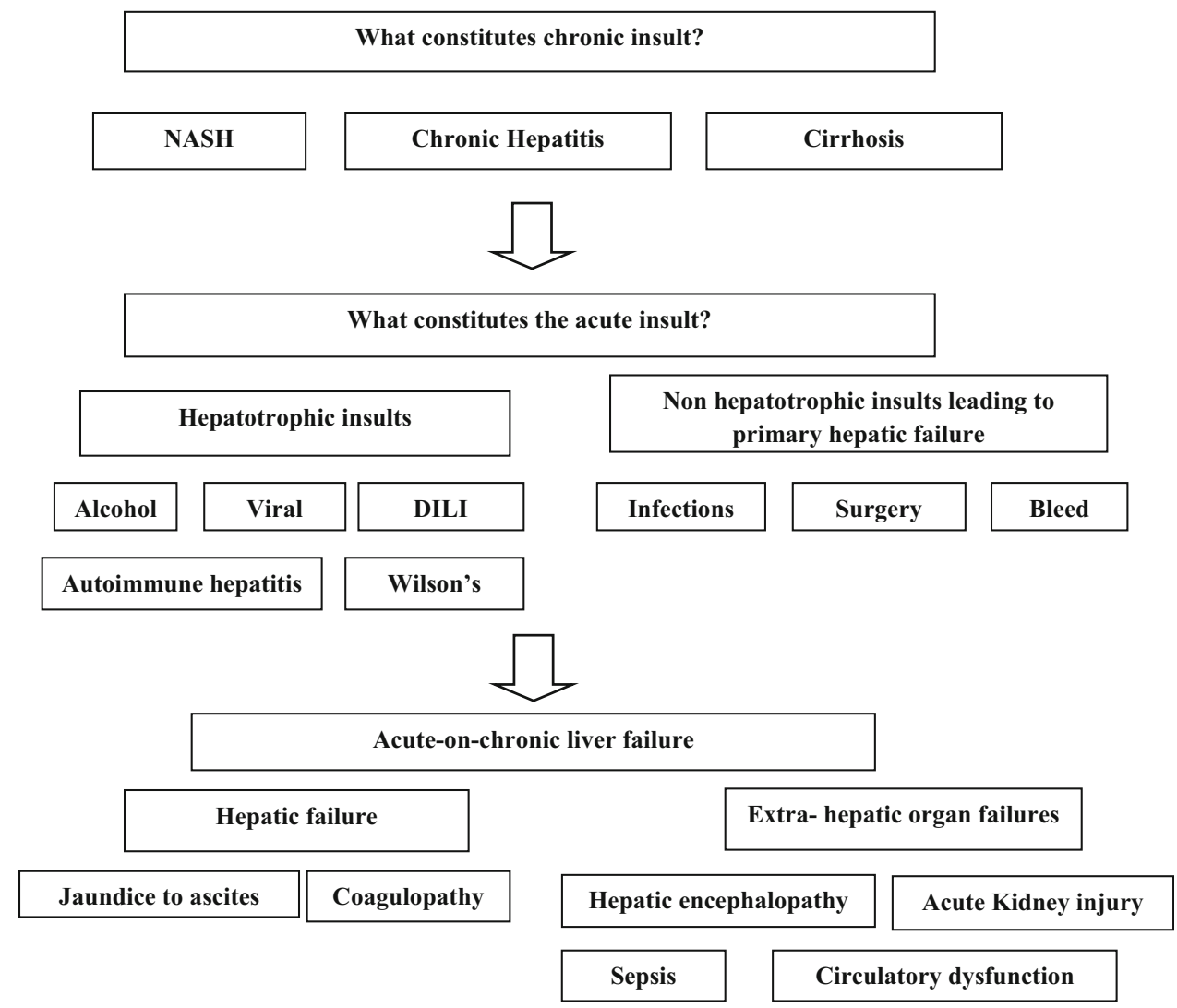

mortality rates were at different time points. A mortality rate of more than $33 \%$ at 4 weeks was considered to be significant allowing recovery to less than two-thirds of the patients. Using these criteria, the data showed that more than $50 \%$ patients of ACLF die by week 4. It was, therefore, unanimously agreed that the 4-week (28 days) period should be maintained as per the initial definition for defining the impact of an acute event.

Efforts were made in light of all the available data on defining the nature of acute event. The acute insult could vary depending on the geographic region and the population under study. These include both infectious and noninfectious causes. These were well characterized in the past. While Hepatitis $\mathrm{B}$ reactivation remains the predominant cause of acute hepatic insult in the East, from the global perspective, the major etiologic agent was alcohol, both in the West and the East. This was a bit unexpected for the Asian countries where alcoholic hepatitis is emerging as a major acute insult and shows the growing westernization of Asia. The predominant causes of acute hepatic insults are shown in Fig. 2. A review of the recent CANONIC study data showed that in the West, the term precipitating event is generally used and probably details of events such as Hepatitis B or superadded Hepatitis A and E are rarely encountered or recorded [2]. However, it was a bit surprising that active alcohol abuse and alcoholic hepatitis were also not the predominant causes. A plausible explanation could be that since the CANONIC study only recorded the acute decompensation of cirrhosis and not the hepatic insults, the major events recorded were only non-hepatic, such as bacterial infections or sepsis. Acute decompensation of cirrhosis is a different entity than ACLF. As the core premise of ACLF is presented as liver failure, the acute insults should be hepatic insults. Both, hepatotropic or non-hepatotropic insults, should manifest in the patient first with liver failure.

Acute hepatic insults of infectious etiology included reactivation of Hepatitis $\mathrm{B}$ virus (HBV) as the leading cause of ACLF in the Asian region [10-19]. Reactivation of HBV could be either spontaneous or due to intensive chemotherapy or immunosuppressive therapy [10, 11], immune restoration after highly active antiretroviral therapy for HIV [12, 13], treatment-related [14], or reactivation of the occult HBV infection by rituximab (anti-CD20)based chemotherapy [15-17]. Similarly, reactivation of Hepatitis $\mathrm{C}$ virus infection has also been reported, especially after immune suppressive therapy [18, 19]. The other very important infectious etiology of the acute event is super-infection with Hepatitis E virus, predominantly in patients in the Indian subcontinent [20-23]. Various bacterial, parasitic, and fungal infections may affect the liver. 
Spirochetal, protozoal, helminthic, or fungal organisms may directly infect the liver, whereas bacterial or parasitic infection may spread to the liver from other sites [24]. These infections may lead to liver failure in patients with underlying chronic liver disease. Among the non-infectious etiologies, alcoholic hepatitis is the major cause of acute deterioration in stable known or unknown chronic liver diseases, more often in the western countries $[25,26]$. It was not clear what should be the interval from the last alcoholic drink to be included as acute insult. Since, after the direct hepatic injury, the immunologic injury starts to decline [27], a period of 28 days was considered adequate for inclusion as the last drink. The issue which remains to be addressed was of binge drinking in patients with ACLF due to recent alcohol intake. It was appreciated that a prospective data collection including the drinking behavior especially in the past 6 months would help decide the influence of drinking behavior on the clinical outcome and help in defining the time frame of what should be considered as an acute insult.

Hepatotoxic drugs and complimentary and alternative medicines (CAM) are important causes for acute and acuteon-chronic liver failure in the Asia-Pacific region [28]. Hepatitis following the use of anti-tubercular drugs was considered to be an important cause of acute insult leading to ACLF. In a proportion of patients, despite a history of use of CAM, the precise nature and injurious influence of the agent cannot be determined. The need for further data on the hepatic injury caused by different herbal preparations needs to be studied.

Acute variceal bleeding has been included as one of the events to define hepatic decompensation in the natural history of cirrhosis [29]. Variceal bleeding has also been taken as an acute insult for ACLF in some western trials of ACLF. It was extensively debated whether to consider variceal bleed as an acute event of ACLF. Since the definition of ACLF includes liver failure, jaundice, and coagulopathy, the variceal bleed should result in liver failure. The liver failure in such patients is mainly due to hepatic ischemia [30] and subsequent bacterial infections [31]. It was discussed that for a patient with portal hypertension and cirrhosis of the liver who presents for the first time with variceal bleed without any previous or present signs or symptoms of chronic liver disease, it would not constitute an acute insult. This is especially relevant if such a patient does not develop any jaundice. The experts discussed the stratification of patients based on the stage of underlying liver disease and the severity of variceal bleed. However, since patients with ACLF never decompensated before and are distinct from patients with decompensated cirrhosis, it is unlikely that a variceal bleed would per se lead to significant liver failure manifesting as jaundice and coagulopathy. Based on the data, it was unanimously agreed that acute variceal bleeding is not an acute hepatic insult unless in the patients where it produces jaundice and coagulopathy defining ACLF.

A scenario may exist that a patient who has already fulfilled the criteria of ACLF, and has been diagnosed ACLF, develops a variceal bleed. In such a patient, variceal bleed would be considered as a complication in the natural history of ACLF.

The issue of other non-hepatotropic insults which have been considered in other studies such as surgery, trauma, insertion of transjugular intrahepatic porto-systemic shunt, transartrial chemoembolization, or radiofrequency ablation for hepatocellular carcinoma was discussed in detail. While there is an indirect connection with each of these, it was debated that a patient who already has cirrhosis with HCC or a cirrhotic who undergoes surgery, and separate risk scores are already in practice and being utilized. The likely potential for hepatic decompensation would vary depending on the nature of intervention and underlying hepatic reserve. It was agreed that non-hepatotropic insults producing direct hepatic insult and ACLF in an otherwise compensated liver disease could be considered as acute hepatic insults $(2 b, C)$. In a proportion of patients in Asia or even in the west, the precise agent(s) leading to acute hepatic insult is not well recognized on routine assessment. In such patients, this should be recorded as such.

\section{Recommendations}

\section{Defining the acute event in ACLF}

The ACLF can develop from one or more clearly defined acute hepatic insults, which can be due to hepatotropic or non-hepatotropic agents/causes. Acute insults vary depending on the geographic region and the population under study. Major etiologic agents responsible for precipitating ACLF are as follows:

\subsection{Hepatotropic viral infections (1a, A).}

1.1.1 Among these, reactivation of Hepatitis B virus (HBV) infection and super-infection with HEV are the major causes of acute insult in ACLF (1a, A).

1.1.2 Among the non-infectious causes, active alcohol consumption (within the last 28 days) remains the commonest cause (1a, A).

1.1.3 Drug-induced liver injury, consumption of complimentary and alternative medicines (CAM), severe autoimmune hepatitis, and flare of Wilson's disease are other causes of acute insult in ACLF (1a, A). 
1.2 Non-hepatotropic insults like surgery, trauma, and viral infections if producing direct hepatic insult could lead to ACLF (2b, C).

1.3 Variceal bleed per se may not qualify as an acute insult for ACLF, and we need more data to ascertain this $(5, D)$.

1.4 In a proportion of patients, the acute hepatic insult may not be identifiable by the current routine assessment (5,D).

\section{Defining the underlying chronic liver disease}

Two aspects were carefully analyzed, what constitutes chronic liver disease, cirrhosis alone or non-cirrhotic chronic liver diseases, and the etiology of the chronic liver disease.

The degree of hepatic fibrosis and the functional hepatocellular mass remains heterogeneous in patients with the chronic hepatitis $[32,33]$. Even in patients with stage IV disease, critical mass varies according to the parenchymal reserves. Modified Laennec Scoring System divides stage IV further, according to the thickness of septa into three, ending up in six stages altogether $[34,35]$. Moreover, ACLF is not equivalent to the acute decompensation of cirrhosis, which is the result of parenchymal extinction. Majority of the ACLF patients present with liver failure without any previous assessment of liver disease. It is not possible to distinguish accurately patients with different degree of fibrosis at this point in time. The liver with any significant degree of fibrosis, with activated stellate cells, and infiltrated by the inflammatory cells, is expected to respond in a different way to the acute insult compared to the liver without inflammatory infiltrate [36].

The NAFLD is the leading cause of donor rejection in liver transplantation [37]. Experience from liver transplantation centers shows that steatosis $>30 \%$ in the donor liver is associated with a higher risk of primary nonfunction and graft initial poor function as compared to grafts with no or $<30 \%$ steatosis [38]. Patients with metabolic syndrome and fatty liver, diabetics, male patients of age $>45-50$ years, patients with obesity, and dyslipidemia have the increased risk of fibrosis [39]. While cirrhosis could be a late event, a large proportion of them may have stage 2 or 3 fibrosis. Hence, NASH is indeed an important cause of chronic liver disease [40]. Furthermore, in the East, a large proportion of patients do have reactivation of chronic Hepatitis B. In these patients, while liver failure and ACLF-like presentation does develop, cirrhosis is not necessarily present. The AARC data, based on the liver biopsy studies, corroborated the facts that a fair proportion of patients with ACLF do not have underlying cirrhosis, but still carry a poor prognosis, with mortality above $33 \%$ at 4 weeks. Based on the available data, the published literature and the validity of the 2009 consensus on including the non-cirrhotic chronic liver disease were reaffirmed.

Accurate and reliable assessment of underlying CLD in the setting of ACLF is important for the subsequent management and need for liver transplant in these patients. Diagnosis of chronic liver disease in the setting of ACLF is made by history, physical examination, and previously available or recent laboratory, endoscopic or radiologic investigations [41]. Ultrasound and CT abdomen may pick up CLD. However, to assess the degree of fibrosis in an unshrunken liver would require other radiologic modalities. The current noninvasive tests cannot clearly diagnose the presence of chronic liver disease in the presence of inflammation and liver failure. Hence, liver biopsy through the transjugular route remains an important tool to confirm the stage of fibrosis and presence of cirrhotic or non-cirrhotic liver disease.

A liver biopsy through the transjugular route may be of help when the presence of already underlying CLD and the cause of liver disease are not clear. The liver biopsy may highlight the etiology, stage of fibrosis and prognosis, and outcome in patients with ACLF [42]. In addition, transjugular access directly into the hepatic vein allows the hepatic venous pressure gradient to be measured (HVPG). There is a risk of bleeding leading to hemobilia, hemoperitoneum, and hepatic hematoma in the setting of the deranged clotting profile [43]. The need of liver biopsy in ACLF should therefore be individualized. Standardization of liver biopsy assessment would help a uniform approach to the diagnosis and treatment for CLD and the acute insult.

There is a need to have reliable noninvasive tools to assess the severity of fibrosis in a previously undiagnosed CLD. Ultrasound and CT abdomen may pick up CLD. However, to assess the degree of fibrosis in an un-shrunken liver would require other radiologic modalities. Transient elastography (fibroscan) is a good modality to detect fibrosis radiologically [44]. However, the liver tissue stiffness may also increase with hepatitis, steatosis, and inflammation present in the ACLF setting [45].

The second issue was about the etiology of chronic liver disease and cirrhosis in the Asian-Pacific region. Experts reviewed the data from the AARC, and the etiologic profile of cirrhosis in ACLF was found to be similar to the etiology of cirrhosis in general in the respective countries [26, $46,47]$. With the rising incidence of obesity and NAFLD, proportion of burnt-out NASH presenting as cryptogenic cirrhosis is also increasing [48-50].

Viral serology and nucleic acid testing are required to identify viral etiology. Specialized tests to rule to diagnose metabolic and autoimmune diseases would be needed as well. The presence of stigmata of liver disease on clinical examination, low platelets, evidence of synthetic dysfunction in 
previous reports, and altered AST/ALT ratio in previous reports should prompt the diagnosis of the presence of CLD $[51,52]$.

\section{Role of liver histology in ACLF}

Since the previous consensus statement, new data and insights into the liver histopathology have become available. The main questions which were addressed were as follows: (1) is liver biopsy feasible and safe in ACLF, (2) can liver biopsy help to differentiate ACLF from ALF and chronic liver disease, (3) are there any histologic predictors of outcome in ACLF, such as need for liver transplantation or mortality, and (4) are there any differences in regenerative response in sequential biopsies of survivors and non-survivors?

Percutaneous liver biopsy is generally not feasible in patients with ACLF due to coagulopathy and ascites. Transjugular liver biopsy (TJLB), on the other hand, is considered relatively safe and can help assess stage of fibrosis and severity of hepatic injury. For example, severity of alcoholic hepatitis in alcoholic liver disease related ACLF can be assessed only by liver biopsy [53]. It can provide clues to the underlying acute insult as in Wilson's disease, malignancy, autoimmune hepatitis, DILI, and NASH.

Differentiating ALF and chronic hepatitis with flare is based on the findings of fibrous bands (spurs and bridges) and ductular proliferation. Features of cholestasis and bile duct proliferation are more common in patients with acute injury (classical features of acute hepatitis along with cellular and ductular cholestasis are indicative of acute injury). Differentiation between cirrhosis with acute deterioration and compensated cirrhosis is based on the presence of necrosis and features of acute hepatitis in the former group of patients [42, 53]. It was proposed that the diagnostic stains for fibrosis and necrosis should be mentioned. It was also proposed that connective tissue stains (especially Shikata's orcein stain) should be done in all such cases for differentiating necrosis from fibrosis.

Liver histopathology could also be very useful in prognosticating the outcome in a patient with ACLF [42, $53,54]$. The extent of necrosis, liver damage, and fibrosis is helpful. The presence of ductular bilirubinostasis on liver biopsy defined as the presence of bile plugs in dilated ductules at the interface between the portal tract and parenchyma predicted a poor outcome and a high potential for the development of infections in ACLF. While ballooning was helpful, suggestive of regenerating potential, the presence of eosinophilic degeneration of hepatocytes was not a favorable feature. Standardization of liver biopsy assessment is essential for a uniform approach to the diagnosis and treatment for CLD and acute insult.
Liver regeneration is considered to play an important role in ACLF as prognosis can be improved if the critical threshold of functional liver cell mass is regained. Decompensated cirrhosis is considered irreversible owing to the loss of regeneration potential. Liver histology can provide morphologic evidence supporting these concepts and for assessing regenerative potential and prognosis [55]. In this study, immunohistochemical study of the two levels of regenerative response in liver failure revealed that proliferating hepatocytes were significantly more in ALF in comparison with ACLF $(p<0.001)$ and CHD $(p<0.001)$. Average proliferating hepatocytes were $24 \pm 17,2.6 \pm 1.8$, and $2.8 \pm 2.0 \mathrm{in} \mathrm{ALF}$, ACLF, and CHD, respectively.

There is significant relationship between HSCs and the presence of HPCs, indicating a possible dynamic role of HSCs in liver regeneration and pathobiology of ACLF [56]. Liver biopsy is an important mode of understanding and validating the results of clinical trials exploring various therapeutic options, e.g., mobilization of bone marrowderived stem cells with granulocyte colony-stimulating factor (GCSF) [57].

\section{Recommendations}

\section{Defining the underlying chronic liver disease}

Both cirrhotic and non-cirrhotic chronic liver diseases qualify as chronic liver diseases.

2.1 The common underlying chronic liver diseases include alcohol, Hepatitis B, Hepatitis C, NAFLDrelated chronic liver disease, or cirrhosis of the liver (1a, A).

2.2 Chronic hepatitis and/or significant fibrosis without cirrhosis should be taken as a chronic liver disease, if such a patient presents as ACLF (1b, C).

2.3 NAFLD-related chronic hepatic injury; NASH, if associated with significant fibrosis, should be taken as a chronic liver disease in ACLF (1b, B).

2.4 Patients with known previous decompensation with jaundice, hepatic encephalopathy, and ascites should be excluded $(1 \mathrm{~b}, \mathrm{C})$.

2.5 Diagnosis of chronic liver disease and cirrhosis in the setting of ACLF is made by history, physical examination and laboratory, and endoscopic or radiologic investigations ( $1 \mathrm{a}, \mathrm{A})$.

2.6 A liver biopsy through the transjugular route may be helpful when the presence of underlying chronic liver disease and/or the cause of chronic liver disease and/or the acute insult are not clear (2a, A).

2.7 The need of liver biopsy in ACLF should be individualized, especially in Alcoholic hepatitis, 
severe autoimmune hepatitis, and flare of Wilson's disease (2b, A).

2.8 Liver biopsy may point out the stage of fibrosis and prognosis, and outcome in patients with ACLF (2b, B).

2.9 Certain histologic parameters are predictors of prognosis of ACLF, like ductular bilirubinostasis, eosinophilic degeneration, and parenchymal extinction (1b, B).

2.10 Standardization of liver biopsy assessment is essential for a uniform approach to the diagnosis and treatment for CLD and acute insult $(5, \mathrm{D})$.

2.11 Noninvasive tools to measure liver stiffness and biomarkers may be with help in identifying patients with advanced fibrosis. Studies are needed to validate the performance of these tests in the setting of $\operatorname{ACLF}(2 b, C)$.

\section{Defining the liver failure in ACLF}

Acute liver failure is generally defined as development of hepatic encephalopathy within 4 weeks of onset of jaundice [3]. Since the basic premise in ACLF is to identify patients with chronic liver disease or cirrhosis presenting as acute liver failure, the time frame for liver failure was kept as 4 weeks.

Two issues were specifically addressed.

Patients with ACLF manifest in varied forms owing to the severity of acute insult and degree of underlying chronic liver disease. In the published reports, patients included as having ACLF had severe jaundice associated with organ failure manifested as either hepatic encephalopathy or hepatorenal syndrome (HRS) [2, 58].

Defining the liver failure in ACLF, therefore, required a detailed consideration of all the existing liver failure scores and the criteria defining liver failure in the organ failure scores such as SOFA and APACHE II. The two main variables are bilirubin and coagulopathy. The two were independently and then collectively analyzed. In the 2009 consensus, the level of bilirubin was considered to be above 5 to define the liver failure. This was taken so as to be inclusive and to define a less severe group of patients.

Serum Bilirubin An analysis of the AARC data revealed that patients with a bilirubin between 5 and $10 \mathrm{mg} / \mathrm{dl}$ also had substantial mortality ranging around $38 \%$. The data for patients below this level were, however, not collected as per the initial definition, but is likely to yield mortality rates below $33 \%$. On the other hand, in the CANONIC study, the level of bilirubin for hepatic failure was taken as $12 \mathrm{mg} / \mathrm{dl}$ so as to determine $15 \%$ mortality at 28 days. If these criteria were applied to the ACLF patients in the Asian region, a much higher mortality was observed in our cohort. Hence, the original value of $\geq 5 \mathrm{mg} / \mathrm{dl}$ was accepted as the cutoff for bilirubin for defining liver failure.

Coagulopathy The presence and degree of coagulopathy as a marker for liver failure was re-evaluated. Coagulopathy is an important hallmark of hepatic dysfunction [59, 60]. Patients with ACLF have complex hemostatic defects leading to a delicate, unstable balance between bleeding and thrombosis [61].

In most of the ACLF studies, PT/INR and platelet count were included to test the coagulation system. The available literature suggests that significant coagulopathy is considered if the INR is $>1.5$ [62]. The mean value of INR in one study has been documented to be $1.7 \pm 0.5$ in the survival group and $2.1 \pm 0.5$ in the non-survival group $(p<0.001)$ [53]. High INR is also found significant in recently classified clinical grades of ACLF-ACLF Grade 1 (1.7 \pm 0.6$)$, Grade $2(2.3 \pm 0.9)$ and Grade $3(2.8 \pm 1.0)$ [2]. Platelet count has been reported to inversely correlate with ACLF grades [20]. The CANONIC study has considered an INR of $>2.5$ as significant and platelets count of $<20,000$. An analysis of the AARC data was done, which showed that an INR between 1.5 and 1.9 was also associated with significant 28-day and 3-month mortality. The difference in the cutoff values correlating with the outcome could be because in the CANONIC study, all the patients had cirrhosis and acute decompensation and causes other than liver failure such as sepsis or renal impairment played a major role. In the AARC data, INR was a reflection of acute liver failure. Hence, after due diligence, the cutoff of coagulopathy of $>1.5$ INR was considered representative and accepted.

Conventional tests only detect the time for initial clot formation, and not assess the propagation, amplification, and termination phases, and also they do not incorporate the cellular elements. Probing the individual component or factor does not reveal the complex and intricate coagulation derangement in liver failure. It also does not reflect the compensatory mechanism in the coagulation system. It requires global coagulation assessment to replicate in clinics. To overcome these limitations, viscoelastic methods (e.g., TEG and Rotem, Sonoclot) have been suggested for global coagulation assessment [61, 63]. These tests measure the broad areas of initial clot formation, clotfibrin interaction, fibrin polymerization, platelet-clot-fibrin interaction, and fibrinolysis. However; VET does not reveal the thrombin generation capacity that is the most important component around which the whole coagulation cascade revolves. Thrombin generation assay (TGA) by Calibrated automated thrombogram (CAT) is being increasingly recognized as a versatile tool to investigate the patients with hypo or hypercogulable phenotypes in liver diseases [64, 65]. More translational and clinical research is needed to define the coagulopathies in $\operatorname{ACLF}(2, \mathrm{~B})$. 
Development of clinical ascites and/or encephalopathy has been conventionally taken as evidence of hepatic failure [1]. Ascites and hepatic encephalopathy were not seen in all the patients, and therefore, the presence of either of them was accepted for the definition of ACLF. In the AARC data, ascites was present in $91 \%$ and hepatic encephalopathy in about $45 \%$ of the patients at presentation.

The data were further analyzed to see whether a shorter interval of 2 weeks instead of 4 weeks is a better cutoff for predicting mortality in patients who developed ascites. The AARC data showed that patients who developed ascites within 2 weeks of onset of jaundice, the mortality, was higher.

\section{Grade of liver failure}

Like in many conditions in medicine, such as the NYHA classification for heart failure [66], severity of a disease or variable can be defined to predict the outcome of the disease. Using the four variables, bilirubin, INR, ascites, and hepatic encephalopathy, a simple scoring system may be helpful for making treatment strategies.

The AARC data base was extensively analyzed, and a scoring system was used. The liver failure was graded into 3 grades. This, however, needs to be prospectively evaluated.

\section{Recommendations}

\section{Defining the liver failure in ACLF}

3.1 Jaundice (serum bilirubin $\geq 5 \mathrm{mg} / \mathrm{dl}[\geq 85 \mu \mathrm{mol} / \mathrm{l}]$ ) and coagulopathy (INR $\geq 1.5$ or prothrombin activity $\leq 40 \%$ ) are mandatory parameters to assess liver failure $(2 \mathrm{a}, \mathrm{B})$.

3.2 Ascites and/or encephalopathy as determined by physical examination also reliably reflect significant hepatic functional impairment $(2 \mathrm{~b}, \mathrm{~B})$.

3.3 There is a need for classifying liver failure into different grades to predict the outcome of liver failure per se independent of failure of other organs; the latter follow the primary hepatic insult. The most predictive variables to accurately predict the outcome of hepatic failure include total bilirubin, INR, and hepatic encephalopathy (2b, C). Intervention studies based on the grade of liver failure may help to improve outcome $(1 \mathrm{a}, \mathrm{C})$.

3.4 Coagulation profile in ACLF: prothrombin time (INR) is a useful prognostic marker in patients with ACLF. However, it is not helpful in predicting the risk of bleeding $(2 \mathrm{a}, \mathrm{B})$. Complex coagulation abnormalities are part of the disease process in ACLF; therefore, probing any single factor or coagulation element to predict the risk of bleeding is not reliable $(2 \mathrm{a}, \mathrm{B})$.

3.5 The assessment of coagulation system by global coagulation methods (viscoelastic technique/thrombin generation test) may be considered as a useful tool for assessing coagulation anomalies in ACLF patients $(2, \mathrm{~B})$.

\section{Sepsis in ACLF}

Sepsis is the syndrome of the systemic inflammatory response of the host to infection. The systemic inflammatory response syndrome (SIRS) is defined by the presence of at least two of the following criteria: (1) altered temperature, (2) elevated respiratory rate or hyperventilation, (3) tachycardia, and (4) altered white blood cell count (high, low, or immature forms) [67]. Sepsis is the most common cause of mortality in most intensive care units (ICUs) [68].

Due to the hyperdynamic circulation and complications of portal hypertension, the currently accepted clinical definition of SIRS and hence sepsis may not be entirely applicable to patients with cirrhosis or ACLF. Hence, a high index of suspicion is required for making a clinical diagnosis of sepsis in these patients.

Bacterial infections are much more common in patients with cirrhosis than in the general population [31]. Further, infections are more frequent in patients with decompensated cirrhosis than in those with compensated cirrhosis or chronic hepatitis [69]. The exact mechanisms of increased susceptibility to infections in cirrhosis are unclear; however, several hypotheses have been suggested. In a recent study, in critically ill non-transplanted patients with ACLF, bacteremia was an independent predictor of poor prognosis regardless of the MELD score and severity of illness represented by APACHE II on multivariate analysis [70].

Patients with sepsis often have a striking presentation with high spiking fevers, shock, and respiratory failure [67]. Hence, the prevailing theory of sepsis for many years was that it represented an uncontrolled inflammatory response [71-73]. However, the results of more than 30 trials of diverse anti-cytokine and anti-inflammatory drugs showed no benefit or even reduced survival rates [74].

The current paradigm regarding the host immune response to sepsis is debated and is a matter of great interest in clinical trials as well as basic science. Two theories have been proposed to describe the host response to sepsis. According to the most accepted theory, both pro-inflammatory and antiinflammatory responses occur early and simultaneously in sepsis, although the net initial effect of these competing processes is typically manifested by an early, dominant, hyper-inflammatory phase characterized by shock, fever, and hyper-metabolism. Subsequently, this initial hyper- 
inflammatory phase evolves over several days into a more protracted immunosuppressive phase [71]. The robustness of the hyper-inflammatory phase depends on numerous factors, including preexisting comorbidities, nutritional status, microorganism load, and virulence factors [72].

According to the second theory, there is rapid and sustained up-regulation of genes that regulate the innate immune response and the simultaneous down-regulation of genes that regulate the adaptive immune response. There is protracted, unabated inflammation driven by the innate immune system with resultant organ dysfunction and failure [73].

Whether sepsis is the cause or a result of liver failure was debated at length. The fact that patients who presented with no SIRS or SIRS subsequently developed SIRS or sepsis over a period of 1-2 weeks, indicating that infection and sepsis develop after liver failure, and unabated inflammation provides an opportunity for infections and sepsis. Non-hepatic infections are also common in patients with ACLF [28]. Neutrophil dysfunction and immune paralysis due to reduced HLA-DR expression have been shown to rapidly develop in ACLF patients [27]. The frequency of intrahepatic myeloid and plasmacytoid dendritic cells is reduced with increased interferon gamma producing CD8 T cells in patients with ACLF. Decreased frequency of DCs and high IFN- $\gamma$ levels correlate with poor patient survival [75].

\section{Recommendations}

\section{Sepsis in ACLF}

4.1 There is a central role of inflammation and dysbalance of innate and adaptive immune responses in ACLF patients.

4.2 It is difficult to differentiate SIRS from early sepsis in cirrhosis.

4.3 Identifying infections in cirrhotics at the earliest and institution of appropriate antibiotics promptly is helpful in preventing progression to sepsis, organ failure, and mortality. The same analogy could be applied to patients with $\operatorname{ACLF}(3 a, C)$.

4.4 Whether sepsis is a consequence of or a cause of liver failure is not clear from the current data on ACLF.

4.5 Sepsis developing in a patient with ACLF has high mortality due to multi-organ dysfunction (1a, A). Severe sepsis/septic shock may be too late in initiating treatment in patients with ACLF (1a, C). The choice of antibacterial therapy should be based on the type, severity, and origin of infection (community acquired, nosocomial, or HCA), and on the local epidemiologic data about antibiotic resistance (MDR) (2a, C).
4.6 "Golden window" is a short period of about 1 week before the onset of sepsis and development of extra-hepatic organ failure in a patient with ACLF. Therapeutic interventions during this period are likely to prevent organ failure and provide a potential opportunity for ameliorating or reversing the hepatic injury and failure $(2 \mathrm{~b}, \mathrm{~A})$.

\section{Renal failure}

Renal failure in patients of ACLF is considered to be a complex and challenging condition that is associated with an ominous prognosis. The EASL-CLIF consortium recently put forth a new definition of ACLF in which kidney dysfunction was used as a defining condition [2]. Hence, renal failure is universally present in patients with ACLF according to the definition by the EASL-CLIF consortium while on the contrary, the APASL definition of ACLF does not incorporate organ failure in its definition [1].

In patients with decompensated cirrhosis, the main abnormality causing renal dysfunction is systemic and splanchnic vasodilatation secondary to portal (or sinusoidal) hypertension that leads to decreased effective arterial blood volume and activation of neurohormonal systems, the rennin-angiotensin aldosterone (RAAS), the sympathetic nervous system, and non-osmotic release of antidiuretic hormone, resulting in sodium and water retention [76-78]. Eventhough the systemic hemodynamic alterations in ACLF are similar to patients with decompensated cirrhotics [79], the pathogenesis of renal dysfunction in ACLF is quite different in these patients as a major role is played by SIRS and subsequent sepsis [80]. Hence, both the circulatory and immune dysfunction are responsible for renal injury in these patients. This has been demonstrated by various studies in the past [58, 81-86].

Studies based on APASL criteria have reported renal dysfunction in $22.8-34 \%$ of patients with ACLF and as high as $51 \%$ using the more sensitive AKIN criteria [87]. This highlights the fact that a significant number of patients of ACLF based on APASL criteria who do not have renal dysfunction (using even the most sensitive criteria to detect renal involvement) would definitely be missed if renal dysfunction is considered in the definition.

In a recent study, comparing renal dysfunction in patients with ACLF to decompensated cirrhotics, a higher prevalence, rapid progression to tubular damage, and mortality was seen in ACLF patients with AKI as compared to the decompensated cirrhosis, which reflects a different pathogenetic basis, natural course, and evolution of AKI and its prognostic implication in these patients. Further, in this study, a significantly higher prevalence of sepsis-related AKI was noted in patients with ACLF as 
compared to decompensated cirrhotics, and similar to patients with cirrhosis, patients with hepatorenal syndrome had the worst survival among all causes of AKI. Patients of ACLF with hepatorenal syndrome in this study were also shown to have an inferior response to vasoconstrictors, a higher incidence of side effects requiring drug discontinuation, progression to tubular damage, and mortality as compared to cirrhotics highlighting the need to devise different management algorithms for these patients because almost two-thirds of these patients were non-responders to standard medical treatment [88]. There is also a potential to look at the role of biomarkers of tubular damage namely N-GAL, Kim-1, IL-18, and L-FABP to differentiate functional AKI or HRS from structural AKI, i.e., ATN in these patients [89] as ATN or structural kidney damage may necessitate the need of simultaneous liver-kidney transplant as against liver transplant alone for HRS [90].

Recommendations

\section{Renal failure in ACLF}

5.1 AKIN criteria should be used for the diagnosis and prognostication of AKI in ACLF patients (2b, C).

5.2 AKI is more common and rapidly progressive in patients with ACLF as compared to decompensated cirrhosis and is associated with significantly worse outcome $(3 b, C)$.

5.3 Serum creatinine levels $1-1.5 \mathrm{mg} / \mathrm{dl}$ or AKIN I are also associated with significant mortality in ACLF (2b, C).

5.4 The presence of SIRS, high bilirubin, and hepatic encephalopathy are associated with increased risk of development and progression of AKI. Early goaldirected strategies for the prevention of AKI are warranted $(3 \mathrm{~b}, \mathrm{C})$.

5.5 Hepatorenal syndrome is associated with the worst prognosis in patients with ACLF among all causes of AKI, similar to decompensated cirrhosis $(3 \mathrm{~b}, \mathrm{C})$.

5.6 Vasoconstrictor drugs are less effective in patients with ACLF who have volume non-responsive AKI or $\operatorname{HRS}(3 b, \mathrm{~B})$.

5.7 Biomarkers of tubular damage could have a role in patients with ACLF to determine the need for early RRT or artificial liver support $(3 \mathrm{~b}, \mathrm{D})$.

5.8 In patients with cirrhosis hospitalized for an acute decompensation, the presence of kidney dysfunction (associated with any single "non-kidney" organ failure) or kidney failure (as a single organ failure or in combination with other organ failures) is important predictors of poor outcome at 4 weeks $(1 \mathrm{~b}, \mathrm{~B})$.

\section{Hepatic encephalopathy}

The presence of hepatic encephalopathy (HE) within 4 weeks is part of the criteria for defining acute-on-chronic liver failure (ACLF) [1]. In the recent AARC data, hepatic encephalopathy was seen to be present in about $40 \%$ of the patients. Multiple prospective and retrospective studies had shown that hepatic encephalopathy in ACLF patients is associated with higher mortality, especially in those with grades 3-4 encephalopathy, similar to that of acute liver failure (ALF).

The pathophysiology of HE is complex, and impairment of brain energy and development of brain edema appear to be central in the pathogenesis of encephalopathy [91, 92]. Recent data also suggest that neuroinflammation may have a significant role in brain disturbance [93]. Cerebral edema has been observed in ACLF, and even low-grade HE can be detected by CT and MRI. As in ALF, ammonia-focused therapy constitutes the basis of current therapy for hepatic encephalopathy in ACLF [94]. Emerging therapies include therapy for circulatory dysfunction and correction of hyponatremia [95].

\section{Recommendations}

\section{Hepatic encephalopathy in ACLF}

6.1 The HE is present in about $40-50 \%$ of the ACLF patients $(2 \mathrm{~b}, \mathrm{C})$.

6.2 Grades 3-4 HE in patients with ACLF is associated with increased mortality $(2 \mathrm{~b}, \mathrm{~B})$.

6.3 The MRI/CT brain may help in ACLF with Grades 3-4 HE when cerebral edema or intra-cerebral hemorrhage or other brain pathology is suspected (3b, C).

6.4 Lactulose, rifaximin, NH3-lowering strategies remain the main therapy for $\mathrm{HE}$ in patients with cirrhosis (1a, B). More data are needed in ACLF.

\section{Definition of ACLF}

There is no consistent definition of ACLF in the literature. Each study done previously on ACLF has used its own definition, and there is no unanimity in these definitions in terms of criteria for liver failure, the acute event precipitating ACLF, and the diagnosis of underlying chronic liver disease. Since most of these studies were on patients who required liver support devices or liver transplantation, these studies were biased toward including sicker patients in the definition and patients having a mild disease were left out.

A detailed analysis of the definition of liver failure and the need for the defined outcome of high 28-day mortality 
was taken into account. An estimated $33 \%$ mortality at 28 days was considered important. Having analyzed and defined the acute and chronic insults, the time frame, and the criteria of liver failure, development, and course of organ failure and sepsis, the APASL definition of ACLF of 2009 was reassessed. It was reported that this definition has been used in nearly 200 publications from the East and West and has been found to be simple to apply clinical parameters to use and with high degree of predictive ability to define the outcome of a relatively homogenous group of liver failure patients.

The consensus definition is

The ACLF is an acute hepatic insult manifesting as jaundice (serum bilirubin $\geq 5 \mathrm{mg} / \mathrm{dl}$ ( $85 \mathrm{micromol} / \mathrm{l}$ ) and coagulopathy (INR $\geq 1.5$ or prothrombin activity $<40 \%$ ) complicated within 4 weeks by clinical ascites and/or encephalopathy in a patient with previously diagnosed or undiagnosed chronic liver disease/cirrhosis, and is associated with a high 28-day mortality.

\section{Prognostic scores for ACLF}

Two categories of prognostic models are commonly used: first, those evaluating the severity of illness: Acute Physiology and Chronic Health Evaluation (APACHE) II and III, Simplified Acute Physiology Score (SAPS) II, and Mortality Prediction Model II, which are most commonly used [70, 96], and second, models quantifying organ dysfunction and failure: Logistic Organ Dysfunction System, Multiple Organ Dysfunction Score, Organ System Failure (OSF), and Sequential Organ Failure Assessment (SOFA) [97].

The MELD was originally created and validated in patients in whom an acute reversible complication like bacterial infection or azotemia was not present and not designed to predict mortality in an ICU setting [98]. Of the available models, MELD is the most commonly used. In fact, MELD does not account for any of the complications of portal hypertension like ascites and HE, which are common in patients with ACLF [98]. However, MELD is still the most commonly used prediction model. It has been used in the East, in ACLF patients, with HBV reactivation [99-101]. Modifications of MELD score have also been developed to improve the predictive accuracy [102, 103].

A number of logistic regression models based on both laboratory parameters and organ dysfunction have also been described, again mainly for patients from the East. The most popular one seems to be that described by Sun et al. [104]. The study was based on a retrospective review of 204 patients with $\mathrm{ACHBLF}$, in whom the 3-month mortality was $57.8 \%$. A logistic regression model was developed based on the independent factors predictive of prognosis: HRS, liver cirrhosis, $\mathrm{HBeAg}$, prothrombin activity and albumin, and compared to the standard MELD scoring system. The regression model produced a greater prognostic value than MELD ( $c=0.891$ vs. 0.701 ). However, it is to be noted that MELD was calculated according to the original formula, which included reference to etiology of liver disease.

Another logistic regression model [105] using five independent factors, namely $\mathrm{HE}, \mathrm{HRS}$, liver cirrhosis, HBeAg, and PTA, gave an AUC of 0.873 , as compared to a MELD AUC of 0.694.

A dynamic model was recently proposed based on four independent predictors measured at day 0 and 7, namely total bilirubin, platelet count, PTA, and anti-HBe. AUC for the model was 0.856 versus 0.597 for MELD [106].

Sepsis-related Organ Failure Assessment score (SOFA) has gained popularity because multi-organ failure is recognized to be a major factor for increased mortality in critically ill patients from any cause. The SOFA score was designed not to predict outcome but to describe a sequence of complications in the critically ill. Six organs (respiration, coagulation, liver, cardio-vascular, CNS, and renal) are studied dynamically each day to develop a score that can range between 0 and 24 [107].

Since the original paper, SOFA and modifications of SOFA have been used to prognosticate critically ill patients with liver cirrhosis and liver failure [108, 109]. Moreau and colleagues primarily used the chronic liver failuresequential organ failure assessment (CLIF-SOFA) score to identify diagnostic criteria of ACLF in European patients with acute hepatic decompensation [2].

\section{Recommendations}

\section{Prognostic scores in ACLF}

7.1 There are no prospectively validated scoring systems for ACLF. In ACLF-B patients, liver-specific models are described and perform reasonably well, namely MELD, modifications of MELD (AUC 0.7-0.84), and logistic regression models (AUC 0.844-0.891) $(2 b, B)$.

7.2 For critically ill cirrhotic patients admitted to ICU with multi-organ failure, SOFA appears to be the best prognostic model (AUC 0.84) $(2 b, B)$.

7.3 In cirrhotics with acute decompensation, CLIFSOFA score has been validated in Europe $(2 b, C)$. It remains to be prospectively evaluated in patients with ACLF, where liver failure is the predominant presentation. 
7.4 Proposed AARC dynamic model of ACLF is based on MELD and lactate, and is highly specific and sensitive and has better predictive value than MELD or CLIF-SOFA score. (2b, C). However, it needs to be further prospectively validated.

\section{Treatment for ACLF}

\section{Antiviral strategies in ACLF $H B V$ reactivation}

The presence of high HBV DNA ( $\geq 10(5)$ copies/ml/or $\geq 2 \times 10$ (4) IU/ml) is highly sensitive and specific for the diagnosis [110]. Early and rapid reduction in HBV DNA is the essence of therapy [111]. Several studies have indicated that if the reduction in DNA of $>2 \log$ s could be achieved within 2 weeks, the survival could be improved. This could be related to the suppression of hepatocellular necrosis and cytokine release [112].

Besides patients who present with ACLF, it is worthwhile that prophylactic therapy should be considered for HBsAg-positive patients undergoing chemotherapy [113]. There is insufficient data to recommend antiviral therapy for HBsAg-negative and anti-HBcpositive patients with possible reactivation of occult HBV infection [114].

\section{Recommendations}

8.1.1 Nucleos(t)ide analogs should be started immediately in all $\mathrm{HBV}$-infected patients at presentation while waiting for confirmation by HBV DNA level. Potent antiviral drugs, such as tenofovir, entecavir, or telbuvidine, should be used $(2 a, B)$.

8.1.2 Assessment of reduction in HBV DNA level at day 15 after nucleos(t)ide analogs is encouraged; if $<2$ $\log$ reduction, it suggests poor prognosis $(2 a, B)$.

\section{Liver transplantation}

A characteristic feature of ACLF is its rapid progression, the requirement for multiple organ supports, and a high incidence of short- and medium-term mortality of 50-90 \%. The 28-day mortality rate was 15 times higher in patients with ACLF as compared to other chronic liver disease (CLD) patients [1, 2, 58]. Patients with ACLF are susceptible to infection, and early transplant-free survival is very low $[115,116]$. Patients who develop infectious complications (particularly pneumonia and/or sepsis) and patients who receive renal replacement therapy or mechanical ventilation are less likely to undergo liver transplantation. Established sepsis/MODS precludes transplant and is associated with poor outcome.

While there are many predictors of mortality, there are no reliable predictors of reversibility of ACLF. There is an urgent need to identify such variables.

Both deceased and living donor transplants are viable and very useful options with very good results [117]. Liver transplantation results from the East in patients with $\mathrm{HBV}$ reactivation have shown successful 5-year survival above $90 \%$ [118]. In a DDLT setting, the availability of the organ becomes a major concern. In living donor transplant cases, there are no waiting list constraints, and survival has been shown to be comparable to DDLT.

Most patients with ACLF will have one or more organ dysfunction. Whether these could be considered for transplant and what is the outcome when compared with those without organ failure is not clear. Ling et al. and $\mathrm{Xu}$ et al. found that downgrading MELD (to < 30) in ACLF using an artificial liver support system as bridging therapy improved outcomes in the responders to levels similar to those who had upfront liver transplant [119, 120].

Sometimes, patients with ACLF have rapidly worsening liver and renal function needing decision making out with the above time frames for AKI. There is paucity of data on SLK in this subset of patients to make evidence-based recommendations [90].

\section{Recommendations}

8.2.1 No validated criteria and scoring system for early and correct identification of patients with ACLF who would benefit from early liver transplantation.

8.2.2 MELD could be used for patient selection, needs evaluation in $\operatorname{ACLF}(3 a, C)$.

8.2.3 ACLF patients with MELD $>30$ should be considered for urgent transplantation $(2 a, B)$.

8.2.4 Patients with $\mathrm{HBV}$ reactivation with intermediate MELD should be assessed for early transplant if cirrhosis, bilirubin $>10 \mathrm{mg} / \mathrm{dL}$, PT $<40 \%$, and platelet $<100 \times 10^{9} / \mathrm{L}(2 b, C)$.

8.2.5 Organ failure per se should not be a contraindication for transplantation, except if cardiac or pulmonary support needed or rapidly progressing organ failure at day 4 or $7(2 b, C)$.

8.2.6 LDLT/DDLT attain satisfactory long-term survival, even in ACLF patients with high MELD score $(2 b, C)$.

In a large proportion of patients with ACLF, however, liver transplant is not feasible, due to the lack of an organ, a donor, severity of the illness, or other social challenges. There are few alternatives at present to liver 
transplant. There have been promising results of the use of growth factors in such patients. Garg et al. [57] have shown that granulocyte colony-stimulating factor (GCSF) can help in hepatic regeneration by mobilizing bone marrow-derived CD34 + cells. In addition, it significantly reduced the development of sepsis and subsequent multiorgan failure. These data were substantiated in another study from the East in patients with HBV-related ACLF [121].

However, despite the encouraging results and two randomized controlled clinical trials, it was felt the use of these agents should be undertaken only under protocols and more data are required before recommending routine use of these agents.

Liver dialysis and replacement therapy in ACLF

The hepatocellular injury in ACLF is driven to a large extent by a "cytokine burst," with elevated levels of multitude of cytokines, small molecular weight toxins, vasoactive substances that are known to accumulate secondary to the failing liver [122]. There is an additional challenge of the injury due to endotoxin and metabolites released from gut bacteria. These toxins not only potentiate the hepatic injury but also deprive the liver of an environment, which is conducive for regeneration. The released toxins are responsible for the systemic inflammation, loss of adaptive and innate immunity, and cause vital organ dysfunction that affects all the major organs [122].

Extracorporeal liver support therapies are used to bridge the liver until recovery or liver transplantation in patients with ALF and ACLF. Various randomized controlled trials in patients with ACLF have shown improvement in hepatic encephalopathy, hepatorenal syndrome, circulatory dysfunction, and immune dysfunction without improvement in transplant-free survival [123-129]. In the most recent meta-analysis and systematic review, no benefit of MARS treatment in reducing mortality as compared to SMT was noted [130], even though both these meta-analysis have the limitations of enrolling a heterogenous group of patients. However, contrary results were shown by systematic review by Kjaergard et al. where it was seen that ALS reduced mortality by $33 \%$ in patients with ACLF as compared to SMT [131]. More recently, studies have shown that ALS could be an effective form of bridging therapy in patients with ACLF with high MELD scores awaiting liver transplantation and many believe it is a futile exercise in the absence of liver transplant $[119,120]$. These results have been substantiated by the recently published two large European randomized multicentric controlled trials, i.e., HELIOS (for Prometheus) [125] and RELIEF trial (for MARS) [124], that failed to show any benefit with these modalities on short-term transplant-free survival, which was the primary end point of these studies. The foremost reason for no demonstrable survival benefit with the currently available artificial liver support systems is the functional incompetence as most of these provide only the detoxification function of the entire armamentarium of liver functions and thus incorporation of synthetic function by living hepatocytes, i.e., the "bioartificial liver" or therapies to potentiate hepatic regeneration look more realistic. The other major challenge that remains is to decide the timing of therapy so as to derive maximal therapeutic benefit, i.e., whether to consider it before or after the onset of sepsis because by the time multi-organ failure is manifest, the benefits of intervention with these devices is not to be expected.

\section{Recommendations}

8.3.1 Liver dialysis improves bilirubin, HE, HRS in ACLF patients, but not survival $(1 b, A)$.

8.3.2 It can be used as a bridge to transplantation or regeneration in $\operatorname{ACLF}(3 b, C)$.

8.3.3 Studies are needed to decide whether it should be introduced before or after the onset of sepsis $(3 b$, $D)$.

\section{Conclusions}

In summary, the field of ACLF has moved very rapidly in the past 5 years. The availability of large volume of published data from the East and the West has allowed to reassess the initial definitions. The need for having a welldefined homogenous population of patients which reflect the term acute-on-chronic liver failure is at the core. Attempts to abrogate, ameliorate, or reverse the ongoing injury would allow return of hepatic synthetic functions and reversal of the liver damage. Early predictors of mortality and non-reversibility of the condition would pave way to offer priority liver transplantation to such patients. An attempt to converge the thoughts from the East and West is possibly the only way forward to achieve more scientific and timely interventions for such highly sick patients.

Acknowledgements Authors would like to thank Lovkesh Anand, Ankit Bhardwaj, Ajeet Singh Bhadoria, Ashok Choudhury, Devaraj Rangegowda, Ankur Jindal, Rajeev Khanna, Naveen Kumar, Avinash Kumar, R.P. Mathur, R. Sivaramakrishnan, S.M. Shasthry, and Amrish Sahney.

Compliance with ethical requirements and Conflict of interest All procedures followed were in accordance with the ethical 
standards of the responsible committee on human experimentation (institutional and national) and with the Declaration of Helsinki 1975, as revised in 2008 (5). Informed consent was obtained from all patients for being included in the study. Shiv Kumar Sarin, Chandan Kumar Kedarisetty, Zaigham Abbas, Deepak Amarapurkar, Chhagan Bihari, Albert C. Chan, Yogesh Kumar Chawla, A. Kadir Dokmeci, Hitendra Garg, Hasmik Ghazinyan, Saeed Hamid, Dong Joon Kim, Piyawat Komolmit, Suman Lata, Guan Huei Lee, Laurentius A. Lesmana, Mamun Mahtab, Rakhi Maiwall, Richard Moreau, Qin Ning, Viniyendra Pamecha, Diana Alcantara Payawal, Archana Rastogi, Salimur Rahman, Mohamed Rela, Anoop Saraya, Didier Samuel, Vivek Saraswat, Samir Shah, Gamal Shiha, Brajesh Chander Sharma, Manoj Kumar Sharma, Kapil Sharma, Amna Subhan Butt, Soek Siam Tan, Chitranshu Vashishtha, Zeeshan Ahmed Wani, ManFung Yuen and Osamu Yokosuka declare that they have no conflict of interest.

\section{References}

1. Sarin SK, Kumar A, Almeida JA, Chawla YK, Fan ST, Garg H, et al. Acute-on-chronic liver failure: consensus recommendations of the Asian Pacific Association for the Study of the liver (APASL). Hepatol Int. 2009;3:269-282

2. Moreau R, Jalan R, Gines P, Pavesi M, Angeli P, Cordoba J, et al. Acute-on-chronic liver failure is a distinct syndrome that develops in patients with acute decompensation of cirrhosis. Gastroenterology. 2013;144:1426-1437

3. Centre for evidence-based medicine. Levels of evidence. 2001. http://www.cebm.net/index.aspx?o=1047. Accessed 12 Oct 2008

4. O'Grady JG, Schalm SW, Williams R. Acute liver failure: redefining the syndromes. Lancet. 1993;342:273-275

5. Sen S, William R, Jalan R. The pathophysiological basis of acute-on-chronic liver failure. Liver. 2002;22(Suppl 2):5-13

6. Wlodzimirow KA, Eslami S, Abu-Hanna A, Nieuwoudt M, Chamuleau RA. A systematic review on prognostic indicators of acute on chronic liver failure and their predictive value for mortality. Liver Int 2013;33(1):40-52

7. Ferenci P, Lockwood A, Mullen K, Tarter P, Weissenborn K, Blei AT. Hepatic encephalopathy: definition, nomenclature, diagnosis and quantification-final report of the working party at the 11th World Congress of Gastroenterology, Vienna 1998. Hepatology. 2002;25(3):716-721

8. Bajaj JS. Defining acute-on-chronic liver failure: will East and West ever meet. Gastroenterology. 2013;144:1337-1339

9. Olson JC, Wendon JA, Kramer DJ, Vicente A, Jalan R, GarciaTsao G, et al. Intensive care of the patient with cirrhosis. Hepatology. 2011;54:1864-1872

10. Xu L, Tu Z, Xu G, Wang Y, Pan W, Zhan X, et al. Epirubicin directly promotes hepatitis $B$ virus (HBV) replication in stable HBV-expressing cell lines: a novel mechanism of HBV reactivation following anticancer chemotherapy. Mol Med Rep 2014;9(4):1345-1350

11. Mikulska M, Nicolini L, Signori A, Rivoli G, Bono VD, Raiola $\mathrm{AM}$, et al. Hepatitis B reactivation in $\mathrm{HBsAg}$ negative/ $\mathrm{HBcAb}$ positive allogeneic hematopoietic stem cell transplant recipients: risk factors and outcome. Clin Microbiol Infect. 2014;. doi:10. 1111/1469-0691.12611

12. Pei R, Grund S, Verheyen J, Esser S, Chen X, Lu M. Spontaneous reactivation of hepatitis $B$ virus replication in a HIV coinfected patient with isolated anti-Hepatitis B core antibodies. Virol J. 2014;11:9. doi:10.1186/1743-422X-11-9

13. Magalhaes RK, Ferreira D, Salgado M, Pedroto I. Hepatitis B virus reactivation after chemotherapy in an HIV positive patient. J Clin Gastroenterol 2013;47(6):565-566
14. Lim SG, Wai CT, Rajnakova A, Kajiji T, Guan R. Fatal hepatitis $B$ reactivation following discontinuation of nucleoside analogues for chronic hepatitis B. Gut. 2002;51(4):597-599

15. Martin ST, Cardwell SM, Nailor MD, Gabardi S. Hepatitis B reactivation and rituximab: a new boxed warning and considerations for solid organ transplantation. Am J Transplant. 2014; doi:10.1111/ajt.12649

16. Kusumoto S, Tanaka Y, Mizokami M, Ueda R. Strategy for preventing hepatitis $\mathrm{B}$ reactivation in patients with resolved HBV infection following rituximab containing chemotherapy. Hepatology. 2013;. doi:10.1002/hep.26963

17. Tsutsumi Y, Yamamoto Y, Shimono J, Ohhigashi H, Teshima T. Hepatitis B virus reactivation with rituximab containing regimen. World J Hepatol 2013;5(11):612-662

18. Huang M, Huang L. Reactivation of Hepatitis C viral infection after treatment with infliximab. J Clin Gastroenterol 2014;48(2): 189-190

19. Sagnelli E, Pisaturo M, Stanzione M, Messina V, Alessio L, Sagnelli C, et al. Clinical presentation, outcome and response to therapy among patients with acute exacerbation of chronic hepatitis C. Clin Gastroenterol Hepatol 2013;11(9):1174-1180

20. Radha Krishna Y, Saraswat VA, Das K, Himanshu G, Yachha SK, Aggarwal R, et al. Clinical features and predictors of outcome in acute hepatitis $\mathrm{A}$ and hepatitis $\mathrm{E}$ virus hepatitis on cirrhosis. Liver Int 2009;29(3):392-398

21. Mahtab MA, Rahman S, Khan M, Karim MF. Hepatitis E virus is a leading cause of acute-on-chronic liver disease: experience from a tertiary center in Bangladesh. Hepatobiliary Pancreat Dis Int. 2009; 8(1): 50-52

22. Kumar M, Sharma BC, Sarin SK. Hepatitis E virus as an etiology of acute exacerbation of previously unrecognized asymptomatic patients with hepatitis B virus related chronic liver disease. J Gastroenterol Hepatol 2008;23(6):83-87

23. Acharya SK, Sharma PK, Singh R, Mohanty SK, Madan K, Jha $\mathrm{JK}$, et al. Hepatitis E virus (HEV) infection in patients with cirrhosis is associated with rapid decompensation and death. J Hepatol 2007;46:387-394

24. Kim AY, Chung RT. Bacterial, parasitic and fungal infections of the liver, including liver abscess. In Feldman M, Friedman L, Brandt LJ, editors. Sleisenger and Fordtran's Gastrointestinal and Liver Disease. 9th ed. Philadelphia: WB Saunders; 2010. 1351

25. Moreau R, Arroyo V. Acute-on-chronic liver failure: a new clinical entity. Clin Gastroenterol Hepatol. 2014;. doi:10.1016/j. cgh.2014.02.027

26. Garg H, Kumar A, Garg V, Sharma P, Sharma BC, Sarin SK. Clinical profile and predictors of mortality in patients of acuteon-chronic liver failure. Dig Liver Dis 2012;44(2):166-171

27. Wasmuth HE, Kunz D, Yagmur E, Timmer-Stranghöner A, Vidacek D, Siewert E, et al. Patients with acute-on-chronic liver failure display "sepsis-like" immune paralysis. J Hepatol 2005;42(2):195-201

28. Duseja A, Chawla YK, Dhiman RK, Kumar A, Choudhary N, Taneja S. Non-Hepatic insults are common precipitants in patients with acute-on-chronic liver failure. Dig Dis Sci 2010;55(11):3188-3192

29. Ripoll C, Groszmann R, Garcia-Tsao G, Grace N, Burroughs A, Planas R, et al. Hepatic pressure gradient predicts clinical decompensation in patients with compensated cirrhosis. Gastroenterol 2007;133:481-488

30. Amitrano L, Guardascione MA, Martino R, Manguso F, Menchise A, Balzano A. Hypoxic hepatitis occurring in cirrhosis after variceal bleeding: still a lethal disease. J Clin Gastroenterol 2012;46(7):608-612

31. Bruns T, Zimmermann HW, Stallmach A. Risk factors and outcome of bacterial infections in cirrhosis. World J Gastroenterol 2014;20(10):2542-2554 
32. Desmet VJ, Roskams T. Cirrhosis reversal: a duel between dogma and myth. J Hepatol 2004;40:860-867

33. Wanless IR, Wong F, Blendis LM, Greig P, Heathcote EJ, Levy G. Hepatic and portal vein thrombosis in cirrhosis: possible role in development of parenchymal extinction and portal hypertension. Hepatology. 1995;21(5):1238-1247

34. Kim MY, Cho MY, Baik SK, Park HJ, Jeon HK, Im CK, et al. Histological subclassification of cirrhosis using the Laennac fibrosis scoring system correlates with clinical stage and grade of portal hypertension. J Hepatol 2011;55(5):1004-1009

35. Rastogi A, Maiwall R, Bihari C, Ahuja A, Kumar A, Singh T, et al. Cirrhosis etiology and laennac staging system correlate with high portal pressure. Histopathology. 2013;62(5):731-741

36. Libbrecht L, Desmet V, Van Damme B, Roskams T. Deep intralobular extension of human hepatic "progenitor cells" correlates with parenchymal inflammation in chronic viral hepatitis: can "progenitor cells" migrate? J Pathol 2000;192:373-378

37. de Graaf EL, Kench J, Dilworth P, Shackel NA, Strasser SL, Joseph D, et al. Grade of deceased donor liver macrovesicular steatosis impacts graft and recipient outcomes more than the donor risk index. J Gastroenterol Hepatol 2012;27(3):540-546

38. Gabrielli M, Moisan F, Vidal M, Duarte I, Jiménez M, Izquierdo $\mathrm{G}$, et al. Steatotic livers. Can we use them in OLTX? Outcome data from a prospective baseline liver biopsy study. Ann Hepatol 2012;11(6):891-898

39. Angulo P, Keach JC, Batts KP, Lindor KD. Independent predictors of liver fibrosis in patients with nonalcoholic steatohepatitis. Hepatology. 1999;30(6):1356-1362

40. Loomba R, Sanyal A. The global NAFLD epidemic. Nat Rev Gastroenterol Hepatol 2013;10(11):686-690

41. Laleman W, Verbeke L, Meersseman P, Wauters J, van Pelt J, Cassiman D, et al. Acute-on-chronic liver failure: current concepts on definition, pathogenesis, clinical manifestations and potential therapeutic interventions. Expert Rev Gastroenterol Hepatol 2011;5(4):523-537

42. Rastogi A, Kumar A, Sakhuja P, Bihari C, Gondal R, Hissar S, et al. Liver histology as predictor of outcome in patients with acute-on-chronic liver failure (ACLF). Virchows Arch 2011;459(2):121-127

43. Kalambokis G, Manousou P, Vibhakorn S, Marelli L, Cholongitas E, Senzolo M, et al. Transjugular liver biopsy: indications, adequacy, quality of specimens, and complications-a systematic review. J Hep 2007;47:284-294

44. Myers RP, Elkashab M, Ma M, et al. Transient elastography for noninvasive assessment of liver fibrosis: a multicenter Canadian study. Can J Gastroenterol 2010;24(11):661-670

45. Kedarisetty CK, Bhardwaj A, Garg H, Wagle P, Sarin SK. Reduction in liver stiffness at one month is a predictor of survival in acute-on-chronic liver failure. Presented as poster at APASL annual conference 2014 Brisbane

46. Jha AK, Nijhawan S, Rai RR, Nepalia S, Jain P, Suchismita A. Etiology, clinical profile and inhospital mortality of acute-onchronic liver failure: a prospective study. Indian J Gastroenterol 2013;32(2):108-114

47. Seto WK, Lai CL, Yuen MF. Acute-on-chronic liver failure in chronic hepatitis B. J Gastroenterol Hepatol 2012;27(4):662-669

48. Adams LA, Lymp JF, Sanderson SO, Lindor KD, Feldstein A, Angulo P. The natural history of nonalcoholic fatty liver disease: a population based cohort study. Gastroenterology. 2005;129: 113-121

49. Caldwell SH, Crespo DM. The spectrum expanded: cryptogenic cirrhosis and natural history of nonalcoholic fatty liver disease. J Hepatol 2004;40:578-584

50. Bhala N, Angulo P, Van der Poorten D, Lee E, Hui JM, Saracco $\mathrm{G}$, et al. The natural history of nonalcoholic fatty liver disease with advanced fibrosis or cirrhosis: an international collaborative study. Hepatology. 2011;54:1208-1216

51. Sheth SG, Flamm SL, Gordon FD, Chopra S. AST/ALT ratio predicts cirrhosis in patients with chronic hepatitis $\mathrm{C}$ virus infection. Am J Gastroenterol 1998;93(1):44-48

52. Kruger FC, Daniels CR, Kidd M, Swart G, Brundyn K, van Rensberg C, et al. APRI: a simple bedside marker of advanced fibrosis that can avoid liver biopsy in patients with NAFLD/ NASH. S Afr Med J 2011;101(7):477-480

53. Katoonizadeh A, Laleman W, Verslype C, Wilmer A, Maleux G, Roskams T, et al. Early features of acute-on-chronic alcoholic liver failure: a prospective cohort study. Gut. 2010;59(11): 1561-1569

54. Jalan R, Mookerjee RP. Acute-on-chronic liver failure: an early liver biopsy is essential? Gut. 2010;59(11):1455-1456

55. Rastogi A, Maiwall R, Bihari C, Trehanpati N, Pamecha V, Sarin SK. Two-tier regenerative response in liver failure in humans. Virchows Arch. 2014;464(5):565-573

56. Rastogi A, Bihari C, Maiwall R, Ahuja A, Sharma MK, Kumar A, et al. Hepatic stellate cells are involved in the pathogenesis of acute-on-chronic liver failure. Virchows Arch 2012;461(4): 393-398

57. Garg V, Garg H, Khan A, Trehanpati N, Kumar A, Sharma BC, et al. Granulocyte colony stimulating factor mobilizes CD $34+$ cells and improves survival of patients with acute-onchronic liver failure. Gastroenterology. 2012;142(3):505-512

58. Jalan R, Gines P, Olson JC, Mookerjee RP, Moreau R, GarciaTsao G, et al. Acute-on chronic liver failure. J Hepatol 2012;57(6):1336-1348

59. Kar R, Kar SS, Sarin SK. Hepatic coagulopathy-intricacies and challenges; a cross-sectional descriptive study of 110 patients from a superspeciality institute in North India with review of literature. Blood Coag Fibrinolysis 2013;24(2):175-180

60. Lisman T, Leebeck FW. Hemostatic alterations in liver disease: a review of pathophysiology, clinical consequences and treatment. Dig Surg 2007;24(4):250-258

61. Saxena P, Bihari C, Rastogi A, Agarwal S, Anand L, Sarin SK. Sonoclot signature analysis in patients with liver disease with conventional coagulation studies. Adv Hematol 2013;2013: 23751

62. Trey C, Davidson CS. The management of fulminant hepatic failure. In Popper H, Schaffner F, editors. Progress in Liver Diseases. New York: Grune \& Stratton; 1970. 282-298

63. Stravitz RT, Lisman T, Luketic VA, Sterling RK, Puri P, Fuchs $\mathrm{M}$, et al. Minimal effects of acute liver injury/acute liver failure on hemostasis as assessed by thromboelastography. J Hepatol 2011;56:129-136

64. Luddington R, Baglin T. Clinical measurement of thrombin generation by calibrated automated thrombography requires contact factor inhibition. J Thromb Haemostat 2004;2(11):1954-1959

65. Ninivaggi M, Apitz-Castro R, Dargaud Y, de Laat B, Hemker HC, Lindhout T. Whole blood thrombin generation monitored with a calibrated automated thrombogram based assay. Clin Chem 2012;58(8):1252-1259

66. New York Heart Association Inc. New York Heart association classification of Heart failure. In Diseases of the Heart and Blood Vessels: Nomenclature and Criteria for Diagnosis, 6th ed. Boston, Little Brown, 1964. 114

67. Levy MM, Fink MP, Marshall JC, Abraham E, Angus D, Cook D, et al. $2001 \mathrm{SCCM} / \mathrm{ESICM} / \mathrm{ACCP} / \mathrm{ATS} / \mathrm{SIS}$ international sepsis definitions conference. Crit Care Med 2003;31:1250-1256

68. Gustot T, Felleiter P, Pickkers P, Sakr Y, Rello J, Velissaris D et al. Impact of infection on the prognosis of critically ill cirrhotic patients: Results from a large worldwide study. Liver Int 2014. doi: 10.1111/liv.12520 
69. Arvaniti V, D’Amico G, Fede G, Manousou P, Tsochatzis E, Plequezuelo $\mathrm{M}$, et al. Infections in patients with cirrhosis increase mortality four- fold and should be used in determining prognosis. Gastroenterology. 2010;139:1246-1256

70. Duseja A, Choudhary NS, Gupta S, Dhiman RK, Chawla YK. APACHE II score is superior to SOFA, CTP and MELD in predicting the short term mortality in patients with acute-onchronic liver failure (ACLF). J Dig Dis 2013;14(9):484-490

71. Jalan R, Stadlbauer V, Sen S, Cheshire L, Chang YM, Mookerjee RP. Role of predisposition, injury, response and organ failure in the prognosis of patients with acute-on-chronic liver failure: a prospective cohort study. Crit Care 2012;16(6):R227

72. Granja C, Póvoa P, Lobo C, Teixeira-Pinto A, Carneiro A, Costa-Pereira A. The predisposition, infection, response and organ failure (Piro) sepsis classification system: results of hospital mortality using a novel concept and methodological approach. PLoS ONE. 2013;8(1):e53885. doi:10.1371/journal. pone. 0053885

73. Hotchkiss RS, Monneret G, Payen D. Sepsis induced immunosuppression: from cellular dysfunctions to immunotherapy. Nat Rev Immunol 2013;13(12):862-874

74. Kox WJ, Volk T, Kox SN, Volk HD. Immunomodulatory therapies in sepsis. Intensive Care Med 2000;26(Suppl 1):S124 S128

75. Khanam A, Trehanpati N, Garg V, Kumar C, Garg H, Sharma $\mathrm{BC}$, et al. Altered frequencies of dendritic cells and IFN- $\gamma$ secreting $\mathrm{T}$ cells with granulocyte colony stimulating factor (GCSF) therapy in acute-on-chronic liver failure. Liver Int 2014;34(4):505-513

76. Gines P, Schrier RW. Renal failure in cirrhosis. N Engl J Med 2009;361:1279-1290

77. Martín-Llahí M, Guevara M, Torre A, Fagundes C, Restuccia T, Gilabert R, et al. Prognostic importance of the cause of renal failure in patients with cirrhosis. Gastroenterology. 2011;140:488-496

78. Stadlbauer V, Wright G, Banaji M, Mukhopadhyay A, Mookerjee R, Moore K, et al. Relationship between activation of the sympathetic nervous system and renal blood flow autoregulation in cirrhosis. Gastroenterology. 2008;134:111-119

79. Kumar A, Das K, Sharma P, Mehta V, Sharma BC, Sarin SK. Hemodynamic studies in acute-on-chronic liver failure. Dig Dis Sci. 2009;54(4):869-78. doi:10.1007/s10620-008-0421-9

80. Cárdenas A, Ginès P. Acute-on-chronic liver failure: the kidneys. Curr Opin Crit Care 2011;17(2):184-189

81. Ros J, Clària J, To-Figueras J, et al. Endogenous cannabinoids: a new system involved in the homeostasis of arterial pressure in experimental cirrhosis in the rat. Gastroenterology. 2002;122:85-93

82. Altamirano J, Fagundes C, Dominguez M, García E, Michelena J, Cárdenas A, et al. Acute kidney injury is an early predictor of mortality for patients with alcoholic hepatitis. Clin Gastroenterol Hepatol 2012;10(1):65-71

83. Cazzaniga M, Dionigi E, Gobbo G, Fioretti A, Monti V, Salerno F. The systemic inflammatory response syndrome in cirrhotic patients: relationship with their in-hospital outcome. J Hepatol 2009;51:475-482

84. Thabut D, Massard J, Gangloff A, Carbonell N, Francoz C, Nguyen-Khac E, et al. Model for end-stage liver disease score and systemic inflammatory response are major prognostic factors in patients with cirrhosis and acute functional renal failure. Hepatology. 2007;46:1872-1882

85. Holt S, Goodier D, Marley R, Patch D, Burroughs A, Fernando $\mathrm{B}$, Harry D, et al. Improvement in renal function in hepatorenal syndrome with N-acetylcysteine. Lancet. 1999;353:294-295

86. Akriviadis E, Bolta R, Briggs W, et al. Pentoxifylline improves short-term survival in severe alcoholic hepatitis: a double-blind, placebo-controlled trial. Gastroenterology. 2000;119:1637-1648
87. Jindal A, Sarin SK. Acute kidney injury (AKI) at admission and its response to terlipressin as a predictor of mortality in patients with acute-on-chronic liver failure (ACLF). J Hepatol. 2013;58(S1):S89

88. Maiwall R, Kumar S, Vashishtha C, Kumar M, Garg H, Nayak S et al. Acute kidney injury (AKI) in patients with acute-onchronic liver failure (ACLF) is different from patients with cirrhosis. Hepatology. 2013;58(4), Suppl 36A-91A

89. Wan ZH, Wang JJ, You SL, Liu HL, Zhu B, Zang H, et al. Cystatin $\mathrm{C}$ is a biomarker for predicting acute kidney injury in patients with acute-on-chronic liver failure. World J Gastroenterol 2013;19(48):9432-9438

90. Xing T, Zhong L, Chen D, Peng Z. Experience of combined liver-kidney transplantation for acute-on-chronic liver failure with renal dysfunction. Transplant Proc 2013;45(6):2307-2313

91. Donovan JP, Schafer DF, Shaw BW Jr, Sorrell MF. Cerebral edema and increased intracranial pressure in chronic liver disease. Lancet. 1998;351:719-721

92. Poveda MJ, Bernabeu A, Concepcion L, et al. Brain edema dynamics in patients with overt hepatic encephalopathy A magnetic resonance imaging study. Neuroimage. 2010;52:481-487

93. Shawcross DL, Sharifi Y, Canavan JB, Yeoman AD, Abeles RD, Taylor NJ, et al. Infection and systemic inflammation, not ammonia, are associated with grade 3/4 hepatic encephalopathy, but not mortality in cirrhosis. J Hepatol 2011;54:640-649

94. Cordoba J, Ventura-Cots M, Simon-Talero M, Amorós À, Pavesi M, Vilstrup $\mathrm{H}$, et al. Characteristics, risk factors and mortality of cirrhotic patients hospitalized for hepatic encephalopathy with and without acute-on-chronic liver failure. J Hepatol 2014;60:275-281

95. Guevara M, Baccaro ME, Torre A. Hyponatremia is a risk factor of hepatic encephalopathy in patients with cirrhosis: a prospective study with time- dependent analysis. Am J Gastroenterol 2009;104:1382-1389

96. Chatzicostas C, Roussomoustakaki M, Notas G, Vlachonikolis IG, Samonakis D, Romanos J, et al. A comparison of Child Pugh, APACHE II and APACHE III scoring systems in predicting hospital mortality of patients with liver cirrhosis. BMC Gastroenterol 2003;3:7

97. Chen YC, Tian YC, Liu NJ, Ho YP, Yang C, Chu YY, et al. Prospective cohort study comparing sequential organ failure assessment and acute physiology, age, chronic health evaluation III scoring systems for hospital prediction in critically ill cirrhotic patients. Int J Clin Pract 2006;60(2):160-166

98. Kamath PS, Kim WR. The model for end stage liver disease (MELD). Hepatology. 2007;45(3):797-805

99. Yu JW, Sun LJ, Zhao YH, Li SC. Prediction value of model for end stage liver disease scoring system on prognosis in patients with acute-on-chronic liver failure after plasma exchange and lamivudine treatment. J Gastroenterol Hepatol 2008;23(8 Pt 1):1242-1249

100. Yan Y, Mai L, Zheng YB, Zhang SQ, Xu WX, Gao ZL, et al. What MELD score mandates use of entecavir for ACLF-HBV HBeAg negative patients? World J Gastroenterol 2012;18(33):4604-4609

101. Lai J, Lin CS, Yang L, Chen SR, Zhang YQ, Ke WM. Pretreatment HBsAg level and an early decrease in MELD score predict prognosis to lamivudine treatment for $\mathrm{HBeAg}$ negative acute-on-chronic liver failure. Clin Res Hepatol Gastroenterol 2013. doi: $10.1016 /$ j.clinre.2013.10.012

102. Myers RP, Tandon P, Ney M, Meeberg G, Faris P, Shaheen AA, et al. Validation of the five variable model for Model for End stage Liver disease (5vMELD) for prediction of mortality on liver transplant waiting list. Liver Int. 2013; doi:10.1111/liv.12373

103. Bechmann LP, Jochum C, Kocabayoglu P, Sowa JP, Kassalik M, Gieseler RK, et al. Cytokeratin 18 based modification of the MELD score improves prediction of spontaneous survival after 
acute liver injury. J Hepatol. 2010;53(4):639-47. doi:10.1016/j. jhep.2010.04.029

104. Sun QF, Ding JG, Xu DZ, Chen YP, Hong L, Ye ZY, et al. Prediction of the prognosis of patients with acute-on-chronic hepatitis B liver failure using the model for end stage liver disease scoring system and a novel logistic regression model. J Viral Hepatitis 2009;16:464-470

105. Zheng MH, Shi KQ, Fan YC, Li H, et al. A model to determine 3-month mortality risk in patients with acute-on-chronic hepatitis B liver failure. Clin Gastroenterol Hepatol 2011;9:351-356

106. Lin W, Liu X, Ma L, Wei X, Guo H, Meng Q et al. A Dynamic model for predicting outcome in patients with HBV related acute-on-chronic liver failure. Presented at AASLD The Liver Meeting 2013

107. Vincent JL, Moreno R, Takala J, Willatts S, De Mendonça A, Bruining $\mathrm{H}$, et al. The SOFA (Sepsis-related Organ Failure Assessment) score to describe organ dysfunction/failure. Intensive Care Med 1996;22:707-710

108. Das V, Boelle PY, Galbois A, Guidet B, Maury E, Carbonell N, et al. Cirrhotic patients in the medical intensive care unit: early prognosis and long-term survival. Crit Care Med 2010;38: 2108-2116

109. Levesque E, Hoti E, Azoulay D, Ichaï P, Habouchi H, Castaing $D$, et al. Prospective evaluation of the prognostic scores for cirrhotic patients admitted to an intensive care unit. J Hepatol 2012;56:95-102

110. Hoofnagle JH. Reactivation of Hepatitis B. Hepatology. 2009;49:S156-S165

111. Jindal A, Kumar M, Sarin SK. Management of acute hepatitis B and reactivation of hepatitis B. Liver Int 2013;33(Suppl 1): 164-175

112. Sun LJ, Yu JW, Zhao YH, Kang P, Li SC. Influential factors of prognosis in lamivudine treatment for patients with acute-onchronic hepatitis B liver failure. J Gastroenterol Hepatol 2010;25(3):583-590

113. Hwang JP, Lok AS. Management of patients with hepatitis B who require immunosuppressive therapy. Nat Rev Gastroenterol Hepatol. 2013; . doi:10.1038/nrgastro.2013.216

114. Kusumoto S, Tanaka Y, Mizokami M, Ueda R. Strategy for preventing hepatitis $\mathrm{B}$ reactivation in patients with resolved HBV infection following rituximab containing chemotherapy. Hepatology. 2013;. doi:10.1002/hep.26963

115. Bahirwani R, Shaked O, Bewtra M, Forde K, Reddy KR. Acuteon-chronic liver failure before liver transplantation: impact on post transplant outcomes. Transplantation. 2011;92(8):952-957

116. Lin KH, Liu JW, Chen CL, Wang SH, Lin CC, Liu YW, et al. Impacts of pretransplant infections on clinical outcomes of patients with acute-on-chronic liver failure who received living donor liver transplantation. PLoS ONE. 2013;8(9):e72893

117. Chan AC, Fan ST, Lo CM, Liu CL, Chan SC, Ng KK, et al. Liver transplantation for acute-on-chronic liver failure. Hepatol Int 2009;3(4):571-581

118. Chok KSh, Chan SC, Fung JY, Cheung TT, Chan AC, Fan ST, et al. Survival outcomes of right-lobe living donor transplantation for patients with high model for end stage liver disease scores. Hepatobiliary Pancreat Dis Int 2013;12(3):256-262

119. Ling Q, Xu X, Wei Q, Liu X, Guo H, Zhuang L, et al. Downgrading MELD improves the outcomes after liver transplantation in patients with acute-on-chronic hepatitis B liver failure. PLoS ONE. 2012;7(1):e30322

120. Xu X, Liu X, Ling Q, Wei Q, Liu Z, Xu X, et al. Artificial liver support system combined with liver transplantation in treatment of patients with acute-on-chronic liver failure. PLoS ONE. 2013;8(3): e58738

121. Duan XZ, Liu FF, Tong JJ, Yang HZ, Chen J, Liu XY, et al. Granulocyte colony stimulating factor therapy improves survival in patients with hepatitis B virus-associated acute-on-chronic liver failure. World J Gastroenterol 2013;19:1104-1110

122. Jalan R, Williams R. Acute-on-chronic liver failure: pathophysiological basis of therapeutic options. Blood Purif 2002;20: 252-261

123. Hassanein TI, Tofteng F, Brown RS Jr, McGuire B, Lynch P, Mehta R, et al. Randomized controlled study of extracorporeal albumin dialysis for hepatic encephalopathy in advanced cirrhosis. Hepatology. 2007;46(6):1853-1862

124. Banares R, Nevens F, Larsen FS, Jalan R, Albillos A, Dollinger $\mathrm{M}$, et al. Extracorporeal albumin dialysis with the molecular adsorbent recirculating system in acute-on-chronic liver failure: the RELIEF trial. Hepatology. 2013;57:1153-1162

125. Kribben A, Gerken G, Haag S, Herget-Rosenthal S, Treichel U, Betz C, et al. Effects of fractionated plasma separation and adsorption on survival in patients with acute-on-chronic liver failure. Gastroenterology. 2012;142:782-789

126. Mitzner SR, Stange J, Klammt S, Risler T, Erley CM, Bader $\mathrm{BD}$, et al. Improvement of hepatorenal syndrome with extracorporeal albumin dialysis MARS: results of a prospective, randomized, controlled clinical trial. Liver Transplant 2000;6: 277-286

127. Catalina MV, Barrio J, Anaya F, Salcedo M, Rincón D, Clemente G, Bañares R. Hepatic and systemic haemodynamic changes after MARS in patients with acute on chronic liver failure. Liver Int 2003;23(Suppl 3):39-43

128. Laleman W, Wilmer A, Evenepoel P, Elst IV, Zeegers M, Zaman Z, et al. Effect of the molecular adsorbent recirculating system and Prometheus devices on systemic haemodynamics and vasoactive agents in patients with acute-on-chronic alcoholic liver failure. Crit Care 2006;10:R108

129. Guo LM, Liu JY, Xu DZ, Li BS, Han H, Wang LH, et al. Application of Molecular Adsorbents Recirculating System to remove $\mathrm{NO}$ and cytokines in severe liver failure patients with multiple organ dysfunction syndrome. Liver Int. 2003;23(Suppl 3): $16-20$

130. Atienza Merino G. Evaluation of extracorporeal liver support systems in the treatment of liver failure: a systematic review. Gastroenterol Hepatol 2010;33(5):352-362

131. Kjaergard LL, Liu J, Als-Nielsen B, Gluud C. Artificial and bioartificial support systems for acute and acute-on-chronic liver failure: a systematic review. JAMA. 2003;289(2):217-222 